\title{
The Psychological Mechanism of the Influence of Social Exclusion on Risk-Taking Behavior
}

\author{
Pinyu Meng \\ Jinan University, Guangzhou, China \\ Email:m1750272740@163.com
}

How to cite this paper: Meng, P. Y (2020). The Psychological Mechanism of the Influence of Social Exclusion on RiskTaking Behavior. Open Journal of Social Sciences, 8, 146-164. https://doi.org/10.4236/jss.2020.83014

Received: February 19, 2020

Accepted: March 10, 2020

Published: March 13, 2020

Copyright $\odot 2020$ by author(s) and Scientific Research Publishing Inc. This work is licensed under the Creative Commons Attribution International License (CC BY 4.0).

http://creativecommons.org/licenses/by/4.0/

(c) (i) Open Access

\begin{abstract}
This study examined the mediating role of state self-esteem in the effect of social exclusion on risk-taking behavior and the moderating role of self-affirmation in the effect of social exclusion on risk-taking behavior. In experiment 1 , social rejection was manipulated through the Cyberball paradigm, and risk-taking behaviors were measured using Balloon Analogue Risk Task, which confirmed the positive effect of social rejection on risk-taking behaviors. Experiment 2 measured individuals' state self-esteem by questionnaire, and investigated the mediating effect of state self-esteem between social rejection and risk-taking behavior. Experiment 3 tested the regulating effect of self-affirmation by manipulating the subjects' self-affirmation. The main conclusions of the study are as follows: 1) social exclusion significantly affected risk-taking behaviors, and the level of risk-taking behaviors in the social exclusion group was significantly higher than that in the social acceptance group; 2) state self-esteem plays a partial mediating role between social exclusion and risky behaviors; 3 ) self-affirmation moderates the mediating effect of state self-esteem and the direct effect of social exclusion on risk-taking behavior.
\end{abstract}

\section{Keywords}

Social Exclusion, Risk-Taking Behavior, Status Self-Esteem, Self-Affirmation

\section{Introduction}

Seeking social acceptance and maintaining close relationships are two of the most basic human needs (Baumeister \& Leary, 1995). Individuals are willing to invest or sacrifice important resources, such as time and money, to ensure meet those basic needs (Duclos et al. 2013). However, people are often rejected, such as romantic relationships disappear, being ignored in parties or office conversations, the friendly suggestion was turned down, this is the social exclusion from 
a psychological perspective (Maslow, 1968). When individuals experience social exclusion, there are negative consequences (Mead, et al., 2011), Individuals who suffer social rejection experience negative emotions (Legate et al., 2013), overeating (Twenge, Catanese, \& Baumeister, 2002), time perception goes down (Baumeister, Twenge, \& Nuss, 2002), violent crime (Twenge et al., 2001). Social exclusion can threaten people's sense of belonging, self-esteem, self-control and sense of existence, and increase maladaptive behaviors, risky behaviors and risk-taking behaviors.

Social exclusion can increase individual risk-taking behavior, and the excluded can produce more negative emotional expressions such as anger and sadness, as well as lead to decrease of prosocial behavior (Xu \& Wang, 2019; Buelow, Okdie, Brunell \& Trost, 2015). Risky behavior refers to an individual's pursuit of interests regardless of potential risks or negative consequences in the face of approach-avoidance conflict (Ben-Zur, H. \& Zeidner, 2009). The essence of risktaking behaviors is the decision made by individuals to predict future events based on the assessment of losses and gains (Dou, Ne, \& Wang, 2014a). The risk-taking behaviors reflect the risky behavior that an individual will take due to the temptation of interests or needs when facing the conflict.

As a negative interpersonal experience, social exclusion has a negative impact on individuals' psycho-social adaptation (Filipkowski \& Smyth, 2012). Social exclusion has a negative impact on individual self-esteem, leading to a decline in self-esteem of the excluded (Smart Richman \& Leary, 2009), social exclusion is strongly associated with low self-esteem (Leary, Tambor, Terdal, \& Downs, 1995). Self-esteem is an emotional experience in which an individual develops and develops self-love and self-respect based on self-evaluation and demands collective and social respect from others. According to the dynamics of self-esteem, selfesteem can be divided into trait self-esteem and state self-esteem (Leary, 2003), state self-esteem represents the reactivity of self-esteem to the environment, which is the self-esteem of the individual at some point in time, and trait selfesteem is the overall self-esteem of the individual over a long period of time (Zhang \& Li, 2009). Self-esteem is essentially a psychological gauge of interpersonal relationship, monitoring the quality of individual interpersonal relationship. Individual interpersonal relationship status can be reflected through self-esteem, and the relationship between individuals and groups and others can affect their self-esteem (Leary, Tambor, Terdal, \& Downs, 1995, Leary \& Baumeister, 2000). When accepted by others, state self-esteem will increase, and when rejected, state self-esteem will decrease. Self-evaluation will be affected by social feedback, and social rejection significantly reduces state self-esteem (Marshall, Parker, Ciarrochi, \& Heaven, 2014; Leary et al., 2003). Individuals with low self-esteem are less responsive to other people's positive evaluations (Marigold, Cavallo, Holmes, \& Wood, 2014). Fuzzy trace theory indicates that the more attention individuals pay to local details, the more likely they are to have risky behaviors (Brainerd, Stein, Silveira, Rohenkohl, \& Reyna, 2008), Individuals with low state self-esteem 
pay more attention to the compensation of benefits to the threat of self-esteem and offset the threat brought by low state self-esteem by obtaining benefits. Therefore, in the case of low state self-esteem, they are more likely to ignore the possible risks behind the benefits and make more risky behaviors.

Self-affirmation has been shown to reduce self-threat in several areas, such as threatening health risk information, social comparison, and racial discrimination (Harris \& Epton, 2009). When self-esteem is threatened, self-affirmation is an effective strategy to defuse the threat (Schwinghammer, 2006). Self-affirmation reduces the defensive response of individuals with low self-esteem (Jaremka et al. 2011). When an individual's excellent qualities and positive traits are self-affirmed, state self-esteem is significantly improved (Mcqueen \& Klein, 2006; Zhong et al., 2014). It is very important to get rid of the negative effect of social exclusion on psychological behavior to promote the mental and physical health of the excluded individuals and reduce the behavioral deviation. It is particularly necessary to explore whether self-affirmation can effectively alleviate the effect of social exclusion on risky behaviors.

To sum up, on the one hand, social exclusion will reduce the level of individual self-esteem. Self-esteem, on the other hand, is a cause of behavioral biases, and low self-esteem can lead to increased risk-taking behavior. This suggests that social rejection may lead to an increase in risk-taking behavior in individuals through its induced low state of self-esteem. Self-affirmation can reduce the defensive response of individuals with low self-esteem, leading to higher self-esteem levels (Jaremka et al. 2011). Can self-affirmation mitigate the negative effects of increased risk-taking behavior caused by social exclusion? To verify this inference, this study intends to explore the mediating role of state self-esteem in social exclusion and risk-taking behavior, as well as the moderating role of self-affirmation, in order to provide data support for demonstrating the correlation between social exclusion and individual risk-taking behavior, and to mitigate the negative effects of social exclusion through effective intervention.

Four research hypotheses are proposed in this study:

H1: Social exclusion affects individual risk-taking behavior. The level of risktaking behavior of individuals suffering from social exclusion was significantly higher than that of individuals in social acceptance situations.

H2: State self-esteem mediates the effect of social exclusion on risk-taking behavior.

Social exclusion leads to low levels of state self-esteem, which affects risk-taking behavior.

H3: Self-affirmation plays a moderating role in the influence of social exclusion on risk-taking behavior. Under the manipulation condition of self-affirmation, there is no significant difference between the status self-esteem of individuals with social exclusion and social acceptance. In the absence of self-affirmation manipulation, there is a significant difference between social exclusion and social acceptance. 
H4: Self-affirmation regulates the direct effect of social exclusion on risk-taking behavior.

In the condition of self-affirmation manipulation, there is no significant difference between social exclusion and social acceptance. In the absence of self-affirming manipulation, social exclusion of individuals is more risky than social acceptance of individuals.

This study consists of three experiments. Experiment 1 used a single-factor inter-subject experimental design to explore the impact of social exclusion on risk-taking behavior and verify hypothesis 1 . On the basis of the verification of hypothesis 1, experiment 2 used a single-factor inter-subject experimental design to further explore the psychological mechanism, discuss the mediating effect of state self-esteem, and verify hypothesis 2 . Experiment 3 adopted the experimental design of $2 * 2$ between subjects to further explore the regulating effect of self-affirmation to verify hypothesis 3 and hypothesis 4 .

\section{Experiment 1: The Effect of Social Exclusion on Risk-Taking Behavior}

\subsection{Methodology}

\subsubsection{Subjects}

Recruited through the campus network, 111 college students from Guangdong were randomly selected to participate in this experiment, all of whom had no history of mental illness. Participants were randomly assigned to the social acceptance and social exclusion group. After excluding the invalid data, the remaining valid data were 103 , including 44 males. The mean age of the effective subjects was $23.71 \pm 1.43$ years old. There were 49 students in the social exclusion group and 54 in the social acceptance group.

\subsubsection{Research Tools}

\section{1) Manipulation of social exclusion}

Cyberball paradigm (CP) was used to manipulate social exclusion. Participants and two players (virtual players) participated in the online game. The subjects were told that this was a game to test their imagination. They were required to imagine the game situation of the other two players, and to imagine as much as possible. The total number of passes in the game was 30 . The social exclusion group only missed the ball after receiving two at the beginning of the game. Participants in the social acceptance group were randomly assigned to receive the ball during the game, and the catch and pass times were the same as those of the other two players.

At the end of the mission, a retrospective question was used to test the effectiveness of social exclusion manipulation: "given that each player throws an average number of times (i.e., $33 \%$ per player), what percentage do you receive?” If the number of catches reported by the subject does not differ from the actual number, the experimental manipulation is effective.

2) Measurement of risk-taking behavior 
Participants' risk-taking behavior was measured using a Balloon Analogue Risk Task (BART). By pressing a button, the subjects inflated the virtual balloon whose initial score was 0 on the screen. Each time they filled the balloon, the balloon would expand correspondingly and 0.5 points would be obtained. Each balloon can be inflated up to 30 times, with random explosions between 1 and 30 times, and the integral obtained by the balloon is reset to zero. During the process of inflating the balloon, the subjects were faced with two different choices: inflate the balloon, and once the balloon explodes, the accumulated points of the balloon will be reset to zero; stop inflating the balloon, and stop inflating the balloon before it explodes to get the accumulated points of the balloon, which are added to the total accumulated points. A total of 30 balloons were set up in the experiment, and the accumulated points obtained by the subjects were converted into corresponding monetary rewards, which would be the reward of the experiment.

The computer automatically records the number of inflations of the balloon and the explosion point. The inflation rate of the balloon is affected by the explosion point of the balloon. Therefore, the adjusted value is chosen as the dependent variable. The adjusted value refers to the average inflation rate of each balloon except the exploded balloon (BART value total accumulated inflation rate/unexploded balloon rate) (Lejuez et al., 2002; Dou, Nie, Wang, \& Li, 2014a).

\section{3) Measurement of risk preference}

Risk preference may be a variable that affects the experimental results, so it is controlled in the experiment. Risk preference index (RPI) of the subjects was evaluated using the risk preference questionnaire compiled by Hsee and Weber (1997). The questionnaire consists of 14 questions, which are divided into two scenarios: profit and loss. There are 7 items in each scenario. Each item has two options, which respectively represent risk preference and risk avoidance. The degree (or percentage) of risk preference varies among all items, and the subjects have to choose one of the two options. Finally, the cumulative score is used to represent the risk preference level of the subjects. In each case, the level of risk appetite varied between 1 and 8, and the larger the RPI was, the more adventurous the subjects were. The RPI of the profit scenario and the RPI of the loss scenario were added together to obtain the total of the subjects as an index to measure the risk appetite of the subjects.

\subsubsection{Procedures}

The experiment was conducted in a separate way. After the subjects came to the laboratory, they read and signed the informed consent, and were informed that they had the right to quit the experiment at any time. The experimenter conducted the instruction of $\mathrm{CP}$ task, conducted the experiment after the test subjects understood the game rules, and manipulated social exclusion. After completing the CP task, the subjects were asked to fill in retrospective questions to verify the effectiveness of the manipulation. The BART task was then performed to measure the participants' risk-taking behavior. 


\subsection{Data Analysis and Results}

\subsubsection{Social Exclusion Initiation Effectiveness Test}

By asking the retrospective question "assuming that each player throws an average number of times (i.e. 33\% for each player playing 3) what percentage do you get?". Pared-samples T-test conducted between the estimated value and the true value, and the difference was not significant (the exclusion group: $\mathrm{t}=-1.40, p>$ 0.05 ; Social acceptance group: $\mathrm{t}=-1.62, p>0.05$ ), that is, there is no significant difference between the estimated catch probability and the real catch probability. Therefore, the grouping of social exclusion and social acceptance is reasonable.

\subsubsection{Relationship between BART Values and Additional Variables} There was no significant gender difference in BART value, $\mathrm{t}(101)=0.16$, ns.

RPI was significantly positively correlated with BART value $(r=0.473, p<$ 0.01 ), so RPI was included as a covariable in the subsequent analysis.

\subsubsection{The Effect of Social Exclusion on Risk-Taking Behavior}

Covariance analysis was conducted with social interaction groups as independent variables, BART values as dependent variables, and RPI as covariables. The results showed that the BART value of the social exclusion group was significantly higher than that of the social acceptance group $\left(\mathrm{M}_{\text {social exclusion }}=24.60 \pm\right.$ $\left.2.96, \mathrm{M}_{\text {social acceptance }}=21.21 \pm 2.43, \mathrm{~F}(1,100)=8.82, p<0.001, \eta^{2}=0.09\right)$. This indicates that compared with socially accepted individuals, socially rejected individuals are more likely to inflate as much as possible to obtain high rewards in balloon model risk decision-making tasks, that is, social exclusion will increase the risk-taking behavior of individuals.

\subsection{Summary}

Experiment 1 used CP to manipulate social exclusion, and tested the effectiveness of this manipulation through the retrospective question, indicating that the initiation of social exclusion was effective. BART was used to investigate the risky behaviors of the subjects, and its effectiveness in measuring risky behaviors was confirmed in previous studies (Dou et al., 2014b). Experiment 1 to explore the relationship between social exclusion and risk-taking behaviour, it is found that social exclusion affects the risk of individual behavior, social exclusion group's risk-taking level higher than social acceptance's, Individuals who suffer social exclusion engage in more risk-taking behaviour, which can be concluded that the results of this study support the H1, but the psychological mechanism about social exclusion affects risk-taking behavior still needs to be further explored. Social exclusion has a significant effect on individual self-esteem (Williams et al., 2000), and low self-esteem is the cause of many problematic behaviors. Can social exclusion influence risk-taking behaviors by affecting participants' state self-esteem?

Therefore, experiment 2 will be used to probe into the psychological mechanism of social rejection affecting risk-taking behaviors to test whether state self- 
esteem plays a mediating role between social rejection and risk-taking behaviors.

\section{Experiment 2: Mediating Effect of State Self-Esteem on Social Rejection and Risk-Taking Behavior}

\subsection{Methods}

The experiment adopted a single-factor (social exclusion and social acceptance) inter-subject experiment design. The subjects were randomly assigned to two groups. After excluding invalid data, there were 57 people in the social exclusion group and 54 people in the social acceptance group.

\subsubsection{Subjects}

A total of 133 college students were randomly recruited.

All subjects had normal visual acuity or corrected visual acuity. The age range is 18 to 27 . The missing answers and invalid data collection were excluded, leaving 111 valid data, including 41 boys and 70 girls.

\subsubsection{Research Tools}

Manipulation of social exclusion, risk-taking behavior, and risk appetite was measured in the same way as in experiment 1 .

\section{Rosenberg self-esteem scale (SES)}

The scale was compiled by Rosenberg in 1965 and translated and revised into Chinese by. The scale was scored at 4 points. There were 10 items in the scale, with scores ranging from 4 to 1 , with scores ranging from 10 to 40 . The higher the score, the higher the self-esteem. Questions 3, 5, 8, 9 and 10 are entitled "reverse scoring". The scale is widely used due to its high reliability and validity. In the process of use, due to the differences between Chinese and foreign cultures, the researchers suggest that question 8 should be scored positively or eliminated directly. Tian (2006) pointed out that the reliability of the scale was further improved and the structural validity was significantly optimized after deleting the question, and the criterion validity was not affected much. Therefore, in the scoring of this study, the $8^{\text {th }}$ question is removed, and the score range of the questionnaire is 9 - 36 points. This study measures the state self-esteem of the subjects, so the guidance language emphasizes the feelings of the subjects at this specific moment, and the internal consistency reliability coefficient of the scale is 0.897 .

\subsubsection{Procedures}

The experiment was conducted in a separate way. After the subjects came to the laboratory, they read and signed the informed consent, and were informed that they had the right to quit the experiment at any time. The subjects filled in the state self-esteem questionnaire (pre-test), and then conducted the CP task after they understood the rules, and filled in the retrospective question after completing the $\mathrm{CP}$ task to verify the effectiveness of manipulation. Then, fill out the status self-esteem questionnaire again (post-test). After completing the questionnaire, 
BART task was performed to measure the participants' risk-taking behavior.

\subsection{Results and Analysis}

\subsubsection{Social Exclusion Primes Effectiveness Test}

By asking the retrospective question "assuming that each player throws an average number of times (i.e. 33\% for each player playing 3) what percentage do you get?". Pared-samples T-test conducted between the estimated value and the true value, and the difference was not significant (the exclusion group: $\mathrm{t}=$ $-0.923, p>0.05$; Social acceptance group: $\mathrm{t}=-1.137, p>0.05$ ), that is, there is no significant difference between the estimated catch probability and the real catch probability. Therefore, the grouping of social exclusion and social acceptance is reasonable.

\subsubsection{Relationship between BART Values and Additional Variables}

The independent sample t-test was used to examine the gender difference of BART value, and the result was that the gender difference was not significant, $t$ $(109)=0.005$, ns.

RPI was significantly positively correlated with BART ( $r=0.417, p<0.01)$, so RPI was included as a covariable in the subsequent analysis.

\subsubsection{Test the Effect of Social Exclusion on State Self-Esteem}

Through the paired sample t-test, it was found that there was a significant difference in the scores of state self-esteem in the social rejection group $\left(\mathrm{M}_{\text {social exclu- }}\right.$ sion \& pre-test $=21.70 \pm 2.05, \mathrm{M}_{\text {social exclusion \& post test }}=17.04 \pm 4.31, \mathrm{t}=7.63, p<0.01$ ), There was no significant difference between the two groups $\left(\mathrm{M}_{\text {social acceptance \& pre-test }}\right.$ $=21.87 \pm 2.00, \mathrm{M}_{\text {social acceptance \& post test }}=22.11 \pm 4.31, \mathrm{t}=-0.56, n s$.), It showed that social exclusion reduced the subjects' state self-esteem.

\subsubsection{The Effect of Social Exclusion on Risk-Taking Behavior}

Covariance analysis was conducted with subjects as independent variables, BART values as dependent variables, and RPI as covariables. The results showed that the BART value of the social exclusion group was significantly higher than that of the social acceptance group $\left(\mathrm{M}_{\text {social exclusion }}=22.71 \pm 4.27, \mathrm{M}_{\text {social acceptance }}=20.21\right.$ $\left.\pm 3.21, \mathrm{~F}(1,108)=8.751, \eta^{2}=0.31\right)$. Consistent with the results of study 1 , social exclusion had a significant impact on risk-taking behavior, with individuals who experienced social exclusion taking more risks than those who were socially accepted.

\subsubsection{The Mediating Effect Test of State Self-Esteem}

SPSS22.0 was used to conduct independent sample t-test on the self-rating scores of state self-esteem and risk-taking behaviors of the two groups of subjects. The results showed that social exclusion had a significant effect on state self-esteem $\left(\mathrm{M}_{\text {social exclusion }}=6.18 \pm 2.65, \mathrm{M}_{\text {social acceptance }}=4.93 \pm 2.79, \mathrm{t}=0.12, p<0.01\right)$, the self-rating score of state self-esteem in the social exclusion group was significantly lower than that in the social acceptance group. Relation analysis shows 
that social exclusion was negatively correlated with state self-esteem $\left(\mathrm{r}=-0.594^{* *}, p\right.$ $<0.01)$, there was a significant negative correlation between state self-esteem and risk-taking behavior $\left(\mathrm{r}=-0.233^{\star}, p<0.01\right)$, social exclusion is significantly correlated with risk-taking behavior $\left(\mathrm{r}=0.314^{\star *}, p<0.01\right)$, the mediating effect among the three can be further discussed.

According to Wen et al. (2005) proposed by the intermediary function testing procedures, on the basis of the additional control variables, with the experimental manipulation group (social exclusion and social acceptance) after virtualization as independent variable, state self-esteem as intermediary variables, BART values for the dependent variable regression analysis, which in turn inspection path coefficient $c$, coefficient a \& b, and path coefficient c'. The first step is to take experimental grouping as independent variable and BART value as dependent variable for regression. The second step is to take experimental grouping as independent variable and state self-esteem as dependent variable for regression. In the third step, experimental grouping and state self-esteem were taken as independent variables, and BART value was taken as the dependent variable for regression analysis. The data analysis results showed that social exclusion could significantly predict risky behaviors, and the path coefficient $\mathrm{c}$ was significant $(\mathrm{t}$ $=3.453, p<0.001$ ); Social exclusion positively predicted state self-esteem, and the regression coefficient a was significant $(\mathrm{t}=-7.707, p<0.001)$, After the state self-esteem is included in the regression equation, the regression coefficient obtained path coefficient $\mathrm{b}(\mathrm{t}=-0.626, p<0.05) \&$ path coefficient $\mathrm{c}^{\prime}(\mathrm{t}=2.403, p$ $<0.001$ ), This suggests that state self-esteem is a partial mediator between social rejection and risk-taking behavior. The results are shown in Table 1.

\subsection{Summary}

The results of experiment 2 showed that state self-esteem played a partial mediating role in social exclusion and risk-taking behaviors. Individuals suffering from social exclusion experienced lower state self-esteem and exhibited higher risk-taking behaviors, while subjects in the social acceptance group experienced higher state self-esteem and exhibited less risk-taking behaviors. Social exclusion affects individuals' level of risk-taking behavior by affecting their state self-esteem.

Table 1. Mediating effect of state self-esteem between social exclusion and risk-taking behavior.

\begin{tabular}{|c|c|c|c|c|c|c|}
\hline & Dependent variable & Independent variables & $\beta$ & $\mathbf{t}$ & $\mathrm{R}^{2}$ & $\Delta \mathrm{R}^{2}$ \\
\hline 1 (path c) & risk-taking behavior & Social exclusion & 0.31 & $3.45^{\star * *}$ & 0.10 & 0.09 \\
\hline 2 (path a) & State self-esteem & Social exclusion & -0.59 & $-7.70^{* * *}$ & 0.35 & 0.34 \\
\hline 3 (path b) & & State self-esteem & -0.27 & $-.63^{\star *}$ & 0.11 & 0.10 \\
\hline & risk-taking behavior & & & & & \\
\hline (path c') & & Social exclusion & 0.17 & $2.40^{\star *}$ & & \\
\hline
\end{tabular}

Note: ${ }^{* *}$ means $p<0.001,{ }^{* *}$ means $p<0.01,{ }^{*}$ means $p<0.05$ is significant. 
In the Balloon Analogue Risk Task, participants in the social exclusion group were more risky. $\mathrm{H} 1$ and $\mathrm{H} 2$ are supported by the research results.

Social exclusion can bring harm to individuals, making them feel lower self-esteem and increase risk-taking behavior. This negative effect may be offset by internal factors of the individual or by other factors in the external environment. Self-improvement theory (self-enhancement) is pointed out that the drive of the individual with the pursuit of positive self-image and positive self-image and is closely related to human and environment adapt to, is crucial for the development of the individual to be reckoned with (Gregg \& Sedikides, 2014), the effect of individual experience to low self-esteem, the more hope can improve their positive image, so in front of the benefits and risks, choose risk profit, rewarded by making their process, to improve their positive image, depart from China thus disregarding his risk, make a risky behaviour. Self-affirmation can reduce the defensive responses of individuals with low self-esteem (Jaremka et al., 2011). Combined with the results of experiment 2, self-affirmation is expected to regulate the mediating effect of state self-esteem, which will be verified in experiment 3.

\section{Experiment 3: The Moderating Effect of Self-Affirmation}

\subsection{Methods}

The experimental design of 2 (social exclusion, social acceptance) * 2 (self-affirmation, no self-affirmation) was adopted. The subjects were randomly assigned to four groups. After the invalid data were removed, 158 valid data remained. 39 people in the group of Social exclusion \& self-affirmation, 38 people in the social exclusion \& without affirmation group, and 38 people in the social acceptance \& selfaffirmation group, 43 people in the social acceptance $\&$ without self-affirmation group.

\subsubsection{Subjects}

One hundred and seventy-three college students were randomly recruited through the network to be subjects, with a balanced male and female ratio. All the subjects had normal visual acuity and corrected visual acuity.

\subsubsection{Research Tools}

Manipulation of social exclusion, risk-taking behavior and risk appetite were measured in the same way as in experiment 1 . State self-esteem was measured in the same way as in study 2.

\section{Self-affirmation task}

Self-affirmation manipulation reference self-affirmation task by Mcqueen \& Klein (2006), Chatterjee, Irmak \& Rose (2013), Zhong et al. (2014). The subjects in the self-affirmation group wrote about their excellent qualities over their peers, and described in as much detail as possible the cases related to this excellent quality in their own experience. The control group reported eating for 48 hours. Write your answer on a blank sheet of paper for 10 minutes. 


\subsubsection{Procedures}

The experiment was conducted in a separate way. After the subjects came to the laboratory, they read and signed the informed consent, and were informed that they had the right to quit the experiment at any time. Conducted experiments after subjects understood the $\mathrm{CP}$ rules. After completing the $\mathrm{CP}$ task, the subjects were asked to fill in retrospective questions to verify the effectiveness of the manipulation. Then, subjects in the rejection group and the acceptance group were randomly divided into self-affirmation group and non-self-affirmation group. After 10 minutes of recall, the self-esteem scale was used to measure the participants' state self-esteem. The non-self-affirmation group directly measured state self-esteem. The BART task then measured the participants' risk-taking behavior.

\subsection{Results and Analysis}

\subsubsection{The Moderating Effect Test of Self-Affirmation}

Referring to the calculation method of moderating effect proposed by Wen et al. (2005), the moderating effect of self-affirmation on state self-esteem and risk-taking behavior was tested by variance analysis. The results of variance analysis show that the main effect of social exclusion is significant $(\mathrm{F}(1,157)=$ $14.47, p<0.001, \eta^{2}=0.07$ ), The main effect of self-affirmation is significant ( $\mathrm{F}$ $\left.(1,157)=10.44, p<0.01, \eta^{2}=0.05\right)$, Social exclusion and self-affirmation have significant interactive effects $\left(\mathrm{F}(1,157)=5.48, p<0.01, \eta^{2}=0.96\right)$, The simple effect analysis shows that under the condition of self-affirmation, there is no significant difference in individual state self-esteem under the condition of social exclusion and social acceptance $\left(\mathrm{M}_{\text {social exclusion \& self-affirmation }}=21.23 \pm 0.49, \mathrm{M}_{\text {social ac- }}\right.$ ceptance \& self-affirmation $\left.=21.95 \pm 0.47, \mathrm{~F}(1,154)=1.13, p=0.31, \eta^{2}=0.00\right)$; In the absence of self-affirmation, the state self-esteem of individuals with social exclusion is significantly lower than that of individuals with social acceptance $\left(\mathrm{M}_{\text {social }}\right.$ exclusion \& no-self-affrrmation $=18.50 \pm 0.48, \mathrm{M}_{\text {social acceptance \& self-affirmation }}=21.51 \pm 0.45, \mathrm{~F}(1$, 154) $\left.=21.01, p<0.001, \eta^{2}=0.05\right)$.

The moderating effect of self-affirmation on risk-taking behavior was examined, and the results showed that the main effect of social exclusion was significant $\left(\mathrm{F}(1,157)=15.12, p<0.001, \eta^{2}=0.08\right)$, The main effect of self-affirmation is significant $\left(\mathrm{F}(1,157)=7.83, p<0.01, \eta^{2}=0.05\right)$, Social exclusion and self-affirmation have significant interactive effects $(\mathrm{F}(1,157)=5.38, p$ $\left.<0.05, \eta^{2}=0.08\right)$. The results of the simple effect analysis showed that there was no significant difference between the social exclusion group and the social acceptance group in the risk behavior under the condition of self-affirmation $\left(\mathrm{M}_{\text {self-affirmation \& social exclusion }}=21.55 \pm 0.40, \mathrm{M}_{\text {self-affirmation \& social acceptance }}=20.92 \pm 0.41, \mathrm{~F}\right.$ $\left.(1,154)=1.20, p=0.28, \eta^{2}=0.00\right)$; In the absence of self-affirmation, the individual risk behavior of social exclusion is significantly higher than that of social acceptance $\left(\mathrm{M}_{\text {no-self-affirmation \& social exclusion }}=23.61 \pm 0.41, \mathrm{M}_{\text {no-self-affirmation \& social acceptance }}=\right.$ $\left.21.11 \pm 0.38, \mathrm{~F}(1,154)=19.74, p<0.001, \eta^{2}=0.21\right)$. The moderating effect of self-affirmation on state self-esteem and risk-taking behavior is shown in Figure 1. 


\subsubsection{Global Model Test}

Based on the results of the above studies, the PROCESS macro (model 8) was used to test the adjusted mediation model, and the effect value was calculated by bootstrap method with 5000 random samples. The significance of the effect was judged according to whether 0 was included in the $95 \%$ confidence interval. The results show that self-affirmation moderates the mediating effect of state self-esteem and the direct effect of social exclusion on risk-taking behavior. The mediating effect of state self-esteem was analyzed in the condition with and without self-affirmation. The data results showed that the mediating effect of state self-esteem was not significant in the condition with self-affirmation (95\% $\mathrm{CI}=[-0.33,0.38]$, including 0$)$, while in the condition without self-affirmation, the mediating effect of state self-esteem was significant ( $95 \% \mathrm{CI}=[-0.86,-0.16]$, excluding 0). Self-affirmation moderates the direct effect of social exclusion on risk-taking behavior. The data show that, without self-affirmation, social exclusion and social acceptance have a significant difference in risk-taking behavior $(95 \% \mathrm{CI}=[-3.69,-1.33]$, excluding 0$)$, while with self-affirmation, social exclusion and social acceptance have no significant difference in risk-taking behavior $(95 \% \mathrm{CI}=[-1.77,0.50]$, including 0$)$.

\subsection{Summary}

In this study, the level of state self-esteem and risk-taking behavior of subjects under social exclusion was investigated by manipulating self-affirmation. On the basis of study 2, the moderating effect of self-affirmation is further discussed, which is embodied in the moderating effect of state self-esteem and the moderating effect of risk-taking behavior. In terms of state self-esteem, under the condition of self-affirmation, the difference of state self-esteem under the condition of social exclusion is not significant. In the absence of self-affirmation, the status self-esteem of the social exclusion group was significantly lower than that of the social acceptance group. In terms of risky behaviors, individuals in the social
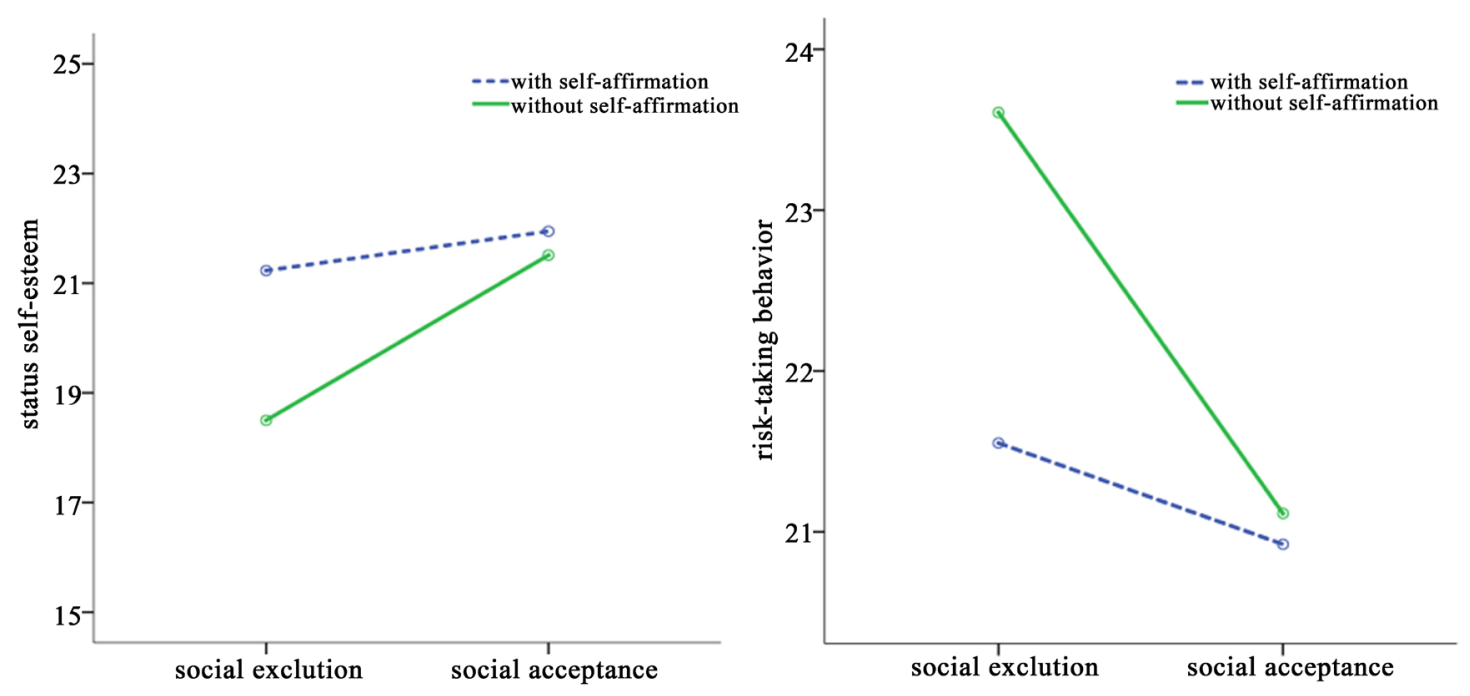

Figure 1. Self-affirmation regulation effect diagram. 
exclusion group showed more risky behaviors and those in the social acceptance group showed less risky behaviors when no self-affirmation manipulation was performed. In the case of self-affirmation manipulation, there was no significant difference in the level of risk-taking behavior between subjects in the social exclusion group and the social acceptance group, indicating that self-affirmation further affected the level of risk-taking behavior by adjusting individuals' state self-esteem, which was shown in the model of this study to be the direct influence of adjusting social exclusion on risk-taking behavior. Self-affirmation can effectively alleviate the decline of state self-esteem caused by social exclusion, so as to promote the scientificity and rationality of decision making and reduce the deviation of decision making. In this study, the deviation of decision making was shown as risk-taking behavior, which provided effective strategies for promoting rational decision making in real life.

The results of this study support $\mathrm{H} 3$ and $\mathrm{H} 4$ that self-affirmation plays a mediating role in the influence of social exclusion on risk-taking behavior. Specifically, the moderating effect of social exclusion on state self-esteem and the moderating effect of risk-taking behavior.

\section{Discuss}

\subsection{Social Exclusion Affects Risk-Taking Behavior}

Experiment 1 preliminarily explored the influence of social exclusion on risk-taking behavior. The results showed that social exclusion would make individuals take more risks, and individuals suffering from social exclusion would show a higher level of risk-taking behavior than those in the social acceptance group. The results of this study are consistent with the findings of $\mathrm{Xu}$ and Yang (2016) that social exclusion enhances individuals' behavioral impulsivity and displays more risk-taking behaviors. Zhong et al. (2017) in the study of risk decision-making in the field of finance and decision making, social exclusion can be divided into long-term and short-term and the discussion of direct social exclusion and indirect social exclusion, found in either type of social exclusion has positive influence on the risk preference of the individual level, when the individual experiences more social exclusion, the risk level is higher. The conclusion of this study is consistent with that of this study, that social exclusion affects risk-taking behavior, and socially excluded individuals engage in more risk-taking behavior.

According to the limited strength resource models, an individual's self-control resources are limited, and when resources are insufficient, self-control failure behaviors will be displayed. Social exclusion can lead to negative psychological experience, which is directly induced by certain coping mechanisms to alleviate such negative experience (Williams et al., 2000). The idea of "cognitive overload" holds that people cope with pain by suppressing negative psychological feelings after experiencing social rejection, and the suppression of negative feelings will occupy cognitive resources, thus affecting the cognition and behavioral perfor- 
mance of the excluded (Baumeister, DeWall, Ciarocco, \& Twenge, 2005). After being rejected by the society, individuals will have self-depletion, which will reduce the application of cognitive resources in the following tasks, leading to the failure of self-control (Zhang, Zhang, \& Wang, 2016). Baumeister et al. (2005) put forward "contract breaking" point of view is also very good explains the social exclusion effect on risk-taking, the view is that there is internal contract between individual and society, social acceptance and social inclusion by individuals as interests, to get through impulse control, but the threat to the people's demand for social acceptance of social exclusion, breaking the internal contract, make interests will not be excluded thinks the impulse control, which is no longer willing to self-control, such as the control of the negative psychological experience caused by social exclusion, will affect their cognitive and behavioral responses. Baumeister et al. (2005) found in their study that subjects in the social rejection group showed decreased self-control, were more likely to be tempted by food and eat more cookies, and were more likely to give up when solving difficult problems, because social rejection led to self-depletion. The essence of individual who, in the face of temptation if you can't call enough cognitive resources for self-control, tend to be tempted, in this study, obtain more points to be seen as a kind of temptation, after their exclusion by the society of individuals using fewer cognitive resources for self-control, so showed more risky behaviour.

\subsection{The Mediating Effect of State Self-Esteem}

Experiment 2 explores the psychological mechanism by which social rejection affects risk-taking behavior. It was found that state self-esteem was a partial mediator of the effect of social exclusion on risk-taking behavior. Individuals who suffered social rejection experienced lower state self-esteem and exhibited higher risk behavior than individuals in the social acceptance group. Social exclusion affects individuals' level of risk-taking behavior by affecting their state self-esteem. According to the theory of self-improvement (self-enhancement), the individual with the pursuit of positive self-image drive, positive self-image and is closely related to human and environment adapt to, is crucial for the development of the individual to be reckoned with in the role (Gregg \& Sedikides, 2014), when the individual experience low self-esteem, also hope to improve their positive image, so in front of the benefits and risks, choose risk profit, rewarded by making their process, to improve their positive image, depart from China thus disregarding his risk, Engage in risky behavior. Self-improvement is an individual's drive for self-affirmation, a way to maintain self-esteem, and a motivation to seek self-evaluation. The core hypothesis lies in the following: people have a need to enhance self-esteem, enhance personal sense of value, seek positive self-knowledge and avoid negative feedback and evaluation (Liu, Sang, \& Dou, 2011).

According to the cognitive dissonance theory (Lawrence \& Festinger, 1962), 
people often seek for consistency in cognition for the sake of their inner peace and harmony. Psychological dissonance has an impact and effect on the construction of their inner world, so people are often pushed to rebuild their cognition and eradicate all disturbances. Individual social exclusion reduces the state of self-esteem, and self-esteem and trait self-esteem levels result in the differences, the resulting drive individual cognitive dissonance to act to restore this coordination, so trying to get profits, to prove the ability of self, to eliminate the uncomfortable feeling, cognitive dissonance in this work, as to obtain benefits associated with the risk of risky behaviour.

Duclos, Wan, and Jiang (2013), the study examines the social exclusion of a key aspect of consumer behavior, the influence of the financial decision-making, consumer pursue higher risks but the choice of higher yield potential, but did not find that the emotion and self-esteem in the effect of work, the study suggests that social exclusion is the cause of individual risk seeking their exclusion by the society of individuals, need more money, to make sure they get what they want from the social system. The results of this study are partly consistent with those of Duclos, Wan and Jiang. That is to say, social exclusion leads to more risky behavior, more risk-taking behavior. The discrepancy is that this study suggests that self-esteem plays a partial mediating role, whereas Duclos's study found no effect of self-esteem on social rejection and risky behaviors. May cause of the inconsistent results is the research object is different, both studies to consumers as the object, and the object of this study is a college student, consumer financial properties superior to the college students, so sensitive about money, therefore tend to choose high returns but has the attributes of the risk of project, external internal money temptation effect is stronger than the effect of self-esteem.

By setting specific gambling situations, Zhang found that people with low self-esteem took more risks than those with high self-esteem (Zhang \& Baumeister, 2006). He believed that individuals with high self-esteem had higher self-evaluation, regarded risks as opportunities, and met challenges with a more positive attitude. Individuals with low self-esteem, on the other hand, are more concerned about the probability of failure and generally have lower self-confidence, so they are more conservative. Josephs et al. (2003) in the study of relation between self-esteem and adventure found that low self-esteem tend to be risk-averse, Josephs sees the low self-esteem will be the future possible failure due to his own ability is insufficient, so the venture would produce the negative psychological feelings, so would tend to choose psychologically feel more security strategy, namely, risk aversion, make less risky behavior than high self-esteem. There are differences between the above studies and the conclusions of this study. This study suggests that social rejection leads to an increase in risk-taking behavior through negative effects on self-esteem, i.e., low self-esteem leads to greater risk-taking. The possible explanation is that cause the differences between the classification of self-esteem, Josephs research middle finger is a trait self-esteem, 
and in this study, measurement is the state of self-esteem, the individual may be due to the gap between trait and state self-esteem create cognitive dissonance, in order to make up for the disorder, need to get satisfy from outside, so the more risky behaviour.

\subsection{The Moderating Effect of Self-Affirmation}

The moderating effect of self-affirmation was discussed in experiment 3 . The moderating effect of self-affirmation was embodied in the moderating effect of state self-esteem and the moderating effect of risk-taking behavior. In terms of state self-esteem, under the condition of self-affirmation, the difference of state self-esteem under the condition of social exclusion is not significant. In the absence of self-affirmation, the status self-esteem of the social exclusion group was significantly lower than that of the social acceptance group. Self-affirmation has been proved to be effective in alleviating self-threat in many fields, such as threatening health risk information, social comparison, racial discrimination, etc. (Schwinghammer, 2006; Harris \& Epton, 2009) when individuals' excellent qualities and positive traits are affirmed by themselves, immediate self-esteem increases significantly (Zhong, Chen, \& Rrosie, 2014).

This study also provides strong evidence for the promotion of self-affirmation to state self-esteem. Individuals suffer from social exclusion, which leads to a decline in state self-esteem. Through self-affirmation, negative consequences caused by low self-esteem can be effectively adjusted. The study suggests that positive self-affirmation can help individuals better adapt.

\section{Conclusion}

This study explored the relationship between social exclusion, risk-taking behavior, state self-esteem and self-affirmation, and established a mediating model among the four, specific conclusions as follows: 1) social exclusion significantly affects risk-taking behavior. The level of risk-taking behavior in the social exclusion group was significantly higher than that in the social acceptance group, that is, social exclusion would improve the level of risk-taking behavior of individuals, while social acceptance would make individuals show lower level of risk-taking behavior. 2) state self-esteem plays a partial mediating role between social exclusion and risky behaviors. Social exclusion makes individuals feel lower state self-esteem and thus exhibit higher risk-taking behaviors. Social acceptance makes individuals feel higher state self-esteem and thus exhibit less risk-taking behavior. 3) self-affirmation plays a moderating role in the influence of social exclusion on risky behaviors. It is manifested in the moderating effect on state self-esteem and the moderating effect on risk-taking behavior.

There are some shortcomings in this paper. Firstly, rewards and losses in risk-taking behaviors are usually relatively balanced (Moore \& Gullone, 1996), and the most favorable choice for individuals is to increase rewards and reduce losses at the same time. In this case, it is unclear whether high self-esteem or low 
self-esteem individuals are more risky, and their risk-taking behaviors should be understood from both reward pursuit and loss avoidance. Then, only CP paradigm is used to manipulate social exclusion in the study. CP paradigm is used to make individuals ignored in the group to express social exclusion, and there are various forms of expression of social exclusion, so other social exclusion paradigms can be used for further research in the future.

\section{Conflicts of Interest}

The author declares no conflicts of interest regarding the publication of this paper.

\section{References}

Baumeister, R. F., \& Leary, M. R. (1995). The Need to Belong: Desire for Interpersonal Attachments as a Fundamental Human Motivation. Psychological Bulletin, 117, 497-529. https://doi.org/10.1037/0033-2909.117.3.497

Baumeister, R. F., Dewall, C. N., Ciarocco, N. J., \& Twenge, J. M. (2005). Social Exclusion Impairs Self-Regulation. Journal of Personality and Social Psychology, 88, 589-604. https://doi.org/10.1037/0022-3514.88.4.589

Baumeister, R. F., Twenge, J. M., \& Nuss, C. K. (2002). Effects of Social Exclusion on Cognitive Processes: Anticipated Aloneness Reduces Intelligent Thought. Journal of Personality and Social Psychology, 83, 817-827. https://doi.org/10.1037/0022-3514.83.4.817

Ben-Zur, H., \& Zeidner, M. (2009). Threat to Life and Risk-Taking Behaviors: A Review of Empirical Findings and Explanatory Models. Personality Social Psychology Review, 13, 109-128. https://doi.org/10.1177/1088868308330104

Brainerd, C. J., Stein, L. M., Silveira, R. A., Rohenkohl, G., \& Reyna, V. F. (2008). How Does Negative Emotion Cause False Memories? Psychological Science, 19, 919-925. https://doi.org/10.1111/j.1467-9280.2008.02177.x

Buelow, M. T., Okdie, B. M., Brunell, A. B., \& Trost, Z. (2015). Stuck in a Moment and You Cannot Get Out of It: The Lingering Effects of Ostracism on Cognition and Satisfaction of Basic Needs. Personality and Individual Differences, 76, 39-43. https://doi.org/10.1016/j.paid.2014.11.051

Chatterjee, P., Irmak, C., \& Rose, R. L. (2013). The Endowment Effect as Self-Enhancement in Response to Threat. Journal of Consumer Research, 40, 460-476. https://doi.org/10.1086/671344

Dou, K., Nie, Y. G., Wang, Y. J., \& Li, J. B. (2014a). Ego Depletion Promotes Risk-Taking Behavior. Journal of Psychological Science, 37, 150-155.

Dou, K., Nie, Y. G., Wang, Y. J., Li, J. B., \& Shen, W. B. (2014b). Ego Depletion Promotes Impulsive Decision: Evidences from Behavioral and ERPs Studies. Acta Psychologica Sinica, 46, 1564-1579. https://doi.org/10.3724/SP.J.1041.2014.01564

Duclos, R., Wan, E. W., \& Jiang, Y. (2013). Show Me the Honey! Effects of Social Exclusion on Financial Risk-Taking. Journal of Consumer Research, 40, 122-135. https://doi.org/10.1086/668900

Filipkowski, K. B., \& Smyth, J. M. (2012). Plugged in but Not Connected: Individuals' Views of and Responses to Online and In-Person Ostracism. Computers in Human Behavior, 28, 1241-1253. https://doi.org/10.1016/j.chb.2012.02.007

Gregg, A., \& Sedikides, C. (2014). Self-Enhancement. In A. C. Michalos (Ed.), Encyclopedia of Quality of Life and Well-Being Research. Dordrecht: Springer. 
https://doi.org/10.1007/978-94-007-0753-5_2634

Harris, P. R., \& Epton, T. (2009). The Impact of Self-Affirmation on Health Cognition, Health Behaviour and Other Health in Elated Responses: A Narrative Review. Social and Personality Psychology Compass, 3, 962-978. https://doi.org/10.1111/j.1751-9004.2009.00233.x

Hsee, C. K., \& Weber, E. U. (1997). A Fundamental Prediction Error: Self-Others Discrepancies in Risk Preference. Journal of Experimental Psychology: General, 126, 45-53. https://doi.org/10.1037/0096-3445.126.1.45

Jaremka, L. M., Bunyan, D. P., Collins, N. L., \& Sherman, D. K. (2011). Reducing Defensive Distancing: Self-Affirmation and Risk Regulation in Response to Relationship Threats. Journal of Experimental Social Psychology, 47, 264-268. https://doi.org/10.1016/j.jesp.2010.08.015

Josephs, R. A., Bosson, J. K., \& Jacobs, C. G. (2003). Self-Esteem Maintenance Processes: Why Low Self-Esteem May Be Resistant to Change. Personality and Social Psychology Bulletin, 29, 920-933. https://doi.org/10.1177/0146167203029007010

Lawrence, D. H., \& Festinger, L. (1962). Cognitive Dissonance. (Book Reviews: Deterrents and Reinforcement. The Psychology of Insufficient Reward). Science, 138, 807. https://doi.org/10.1126/science.138.3542.807

Leary, M. R. (2003). Commentary on Self-Esteem as an Interpersonal Monitor: The Sociometer Hypothesis (1995). Psychological Inquiry, 14, 270-274. https://doi.org/10.1207/S15327965PLI1403\&4_15

Leary, M. R., \& Baumeister, R. F. (2000). The Nature and Function of Self-Esteem: Sociometer Theory. Advances in Experimental Social Psychology, 32, 1-62. https://doi.org/10.1016/S0065-2601(00)80003-9

Leary, M. R., Gallagher, B., Fors, E., Buttermore, N., Baldwin, E., Kennedy, K. et al. (2003). The Invalidity of Disclaimers about the Effects of Social Feedback on Self-Esteem. Personality and Social Psychology Bulletin, 29, 623-636. https://doi.org/10.1177/0146167203029005007

Leary, M. R., Tambor, E. S., Terdal, S. K., \& Downs, D. L. (1995). Self-Esteem as Interpersonal Monitor: The Sociometer Hypothesis. Journal of Personality Social Psychology, 68, 518-530. https://doi.org/10.1037/0022-3514.68.3.518

Legate, N., Dehaan, C. R., Weinstein, N. et al. (2013). Hurting You Hurts Me Too: The Psychological Costs of Complying with Ostracism. Psychological Science, 24, 583-588. https://doi.org/10.1177/0956797612457951

Lejuez, C. W., Read, J. P., Kahler, C. W., Richards, J. B., Ramsey, S. E., Stuart, G. L. et al. (2002). Evaluation of a Behavioral Measure of Risk Taking: The Balloon Analogue Risk Task (BART). Journal of Experimental Psychology: Applied, 8, 75-84. https://doi.org/10.1037/1076-898X.8.2.75

Liu, X.-C., Sang, B., \& Dou, D. H. (2011). Pros and Cons of Self-Enhancement: Theory, Empirical Research, and Application. Advances in Psychological Science, 19, 883-895.

Marigold, D. C., Cavallo, J. V., Holmes, J. G., \& Wood, J. V. (2014). You Can't Always Give What You Want: The Challenge of Providing Social Support to Low Self-Esteem Individuals. Journal of Personality and Social Psychology, 107, 56-80. https://doi.org/10.1037/a0036554

Marshall, S. L., Parker, P. D., Ciarrochi, J., \& Heaven, P. C. L. (2014). Is Self-Esteem a Cause or Consequence of Social Support? A 4-Year Longitudinal Study. Child Development, 85, 1275-1291. https://doi.org/10.1111/cdev.12176

Maslow, A. H. (1968). Health as Transcendence of Environment. Pastoral Psychology, 19, 45-49. https://doi.org/10.1007/BF01835090 
Mcqueen, A., \& Klein, W. M. (2006). Experimental Manipulations of Self Affirmation: A Systematic Review. Self and Identity, 5, 289-354. https://doi.org/10.1080/15298860600805325

Mead, N. L., Baumeister, R. F., Stillman, T. F., Rawn, C. D., \& Vohs, K. D. (2011). Social Exclusion Causes People to Spend and Consume Strategically in the Service of Affiliation. Journal of Consumer Research, 37, 902-919. https://doi.org/10.1086/656667

Moore, S., \& Gullone, E. (1996). Predicting Adolescent Risk Behavior Using a Personalized Cost-Benefit Analysis. Journal of Youth Adolescence, 25, 343-359. https://doi.org/10.1007/BF01537389

Schwinghammer, S. A. (2006). Different Selves Have Different Effects: Self-Activation and Defensive Social Comparison. Personality and Social Psychology Bulletin, 32, 27-39. https://doi.org/10.1177/0146167205277096

Smart Richman, L., \& Leary, M. R. (2009). Reactions to Discrimination, Stigmatization, Ostracism, and Other Forms of Interpersonal Rejection: A Multimotive Model. Psychological Review, 116, 365-383. https://doi.org/10.1037/a0015250

Tian, L. M. (2006). Shortcoming and Merits of Chinese Version of Rosenberg (1965) Self-Esteem Scale. Psychological Exploration, 26, 89-92.

Twenge, J. M., Baumeister, R. F., Tice, D. M. et al. (2001). If You Can't Join Them, Beat Them: Effects of Social Exclusion on Aggressive Behavior. Journal of Personality and Social Psychology, 81, 1058-1069. https://doi.org/10.1037/0022-3514.81.6.1058

Twenge, J. M., Catanese, K. R., \& Baumeister, R. F. (2002). Social Exclusion Causes Self-Defeating Behavior. Journal of Personality and Social Psychology, 83, 606-615. https://doi.org/10.1037/0022-3514.83.3.606

Wen, Z. L., Hau, K., \& Tai, C. L. (2005). A Comparison of Moderator and Their Applications. Acta Psychologica Sinica, 37, 268-274.

Williams, K. D., Cheung, D., \& Choi, T. (2000). Cyberostracism: Effects of Being Ignored over the Internet. Journal of Personality and Social Psychology, 79, 748-762. https://doi.org/10.1037/0022-3514.79.5.748

Xu, S.-H., \& Wang, C.-C. (2019). Habitual Emotional Regulation Strategies Modulate the Effects of Social Exclusion on Decision-making. Chinese Journal of Clinical Psycholo$g y, 27,458-462$.

Xu, S.-H., \& Yang, F. (2016). Mediating Effect of Anger on Relationships between Social Exclusion and Behavior Impulsivity. Chinese Mental Health Journal, 30, 220-225.

Zhang, L., \& Baumeister, R. F. (2006). Your Money or Your Self-Esteem: Threatened Egotism Promotes Costly Entrapment in Losing Endeavors. Personality and Social Psychology Bulletin, 32, 881-893. https://doi.org/10.1177/0146167206287120

Zhang, L., \& Li, Y.-Y. (2009). Review of Sociometer Theory on Self-Esteem. Advances in Psychological Science, 17, 852-856.

Zhang, Y., Zhang, J. J., \&Wang, J. M. (2016). Effects of Social Exclusion on Ego Depletion: The Compensation Effect of Self-Awareness. Psychological Science, 39, 1210-1215.

Zhong, J. N., Ding, Y. F., \& Liu, Y. (2017). The Effect of Social Exclusion on Individual's Risk Preference.

Zhong, Y.-P., Chen, Z.-Y., Luo, X., Wang, X.-A., \& Yi, W.-T. (2014). Effects of Self-Affirmation on Self-Esteem and Self-Evaluation. Chinese Journal of Clinical Psychology, 22, 1005-3611. 